\title{
VARIACIÓNS LOCAIS NA CULTURA POPULAR
}

\author{
Xosé Ramón Mariño Ferro \\ Universidade de Santiago de Compostela
}

\section{LÍMITES XEOGRÁFICOS}

Nun famoso relatorio presentado en 1888 no Instituto de Antropoloxía sobre o método para investigar o desenvolvemento das institucións, Edward Tylor defendeu por primeira vez o uso da estatística. Entre as obxeccións que lle formularon destaca a de Galton, que lle preguntou en que medida se podía asegurar que as tribos ou sociedades comparadas eran independentes; ou sexa, preguntoulle como se fixan os límites entre as culturas. A cuestión segue sen estar resolta satisfactoriamente.

No caso da cultura popular galega, como sucede no resto das culturas do mundo, os límites tampouco están claros. Por outra parte, tampouco foi un asunto que interesase demasiado. Os nosos etnógrafos, levados polos obxectivos dos antropólogos evolucionistas, preocupáronse máis polas orixes históricas que polas conexións xeográficas. Non obstante, penso que non se pode ter unha visión axustada da cultura popular galega se non a situamos no seu contexto. Non se poden valorar axeitadamente as variacións locais se non se ten en conta que a cultura tradicional galega é, no seu conxunto, unha variante da cultura tradicional europea.

Eu comecei os meus traballos sobre a cultura galega centrándome só no noso país. Estudei a bruxería, a medicina popular, as romarías, as festas de ciclo anual, especialmente o Entroido e ultimamente os contos marabillosos. Pero fun comparando con outras nacións de Europa e descubrín que, basicamente, había as mesmas crenzas e as mesmas historias en todo o continente. Sucede que a cultura popular

R. Álvarez, F. Dubert, X. Sousa (eds.): Lingua e Territorio Santiago de Compostela: ILG/CCG, 2006, 131-156 ISBN 84-96530-20-5 
galega é unha variante -con marcada personalidade, iso si- da cultura tradicional europea.

A Galicia campesiña e mariñeira conta cunha tradición cultural rica, cun patrimonio etnográfico abundante e variado. Non se trata -repitodunha tradición exclusiva, senón dunha variante -a nosa variante- da cultura tradicional de Europa, formada na Idade Media utilizando a miúdo, como se sabe, elementos da Antigüidade Clásica.

A cultura tradicional europea ten uns límites temporais e xeográficos variables. $\mathrm{Na}$ Idade Media foi a cultura maioritaria do que se chamaba a Cristiandade. Por suposto, non permaneceu inamovible. Houbo cambios, máis ou menos importantes, tanto na cultura material como nas crenzas. Os cambios foron máis fondos coa chegada da Ilustración e co crecente protagonismo das cidades. A cultura tradicional foi quedando relegada ao mundo rural, se ben sometida, así mesmo, a transformacións máis ou menos profundas.

Se en Galicia a cultura tradicional sufriu menos cambios e se conservou en gran parte ata os nosos días, débese ao máis lento ritmo de modernización do noso país. Mentres noutras nacións o desenvolvemento da moderna sociedade urbana varreuna case por completo, no rural galego, densamente poboado e moi disperso, mantívose viva. Non se esqueza que a principios do século Xx vivía no campo o $90,10 \%$ dos galegos -en 1970, aínda era o $71,50 \%$-, dos que a metade residía en aldeas menores de 25 habitantes.

Cando os primeiros etnógrafos atoparon nos pobos de Europa manifestacións da chamada cultura popular, non recoñeceron nela a antiga cultura tradicional europea. Atribuíronlle diferentes orixes, case sempre afastados no tempo e no espazo. Aínda que pareza incrible, ninguén, ou case ninguén, pensou en relacionala coa tradición específica de Europa. Obsesionados coa prehistoria, cos primitivos, coa Antigüidade Clásica e cos celtas, os antropólogos saltaron a Idade Media e o cristianismo.

A cultura tradicional europea ten personalidade propia. Os seus distintos compoñentes lonxe de seren unha morea de supervivencias illadas como pensaban os evolucionistas, están interrelacionados e forman un conxunto harmónico. As crenzas e ritos de clara procedencia grecolatina, dos que hai moitos, para seren adaptados, sufriron máis ou menos modificacións segundo os casos. 


\section{LÍMITES HISTÓRICOS}

Ademais do plano xeográfico, debemos ter en conta a variable temporal. Os etnógrafos, tamén neste aspecto guiados polos evolucionistas, tenden a pensar que a cultura popular é unha supervivencia de tempos remotos, case inmutable. Pero a realidade é bastante diferente. A cultura popular sofre variacións, variacións que, por suposto, supoñen a aparición duns trazos, a desaparición doutros e supoñen tamén cambios na súa distribución sobre o territorio. Por iso non podemos falar de variacións locais en xeral, senón de variacións locais nunha época determinada. Eu tratarei da distribución de trazos culturais entre os anos vinte e os sesenta do século XX.

Un par de exemplos de cambio no ámbito da cultura material: a forma de mallar. As técnicas para mallar os cereais cambiaron moito ao pasar do século XIX ao XX. E os cambios fóronse estendendo pouco a pouco, facendo variar o mapa de distribución das formas de malla segundo o ano que analicemos.

No período 1926-1965, conviven distintos sistemas de malla: con malladora, con mallo, ao lavadoiro e con cabalos. As malladoras apareceron na primeira década do século. As máis antigas eran case todas manuais ou de malacate -movidas por cabalgaduras-. Pero axiña, a partir de 1912, foron desprazadas polas de motor. A mediados dos anos vinte, a maioría dos labregos malla con malladoras accionadas por motores de gasolina (Fernández de Rota 1984: 119 e 1987b: 67; Sotelo 1993: 342-343). A casa Ajuria vendeu entre 1928 e 1945 unhas 70 máquinas de mallar por ano, agás nos anos da Guerra Civil e a posguerra (Fernández Prieto 1992: 320-322 e 328-331).

Ao final dos anos vinte só as comarcas montañosas descoñecen as malladoras (Fernández Prieto 1992: 190 e 361). Aos Ancares chegan as primeiras nos anos corenta (González Reboredo 1990: 73). No resto de Galicia, se ben a maioría xa mallaba con malladora, as casas pobres, con pouca colleita, seguiron utilizando o mallo (Ramón 1983: 201); tamén en parroquias de escasa produción cerealeira, como Velle, onde en 1931 era o sistema habitual (López 1936: 128). En 1964 usábano aínda algunhas persoas en parroquias de Viana do Bolo, en Donís e outras parroquias de Cervantes, en Villaza-Monterrei, en Salceda de Caselas, etc. (Lisón 1971b: 22, 24, 125 e 135). 
Cando o uso do mallo se debe a que, aínda que a zona sexa cerealeira, a colleita propia é pequena, non ten sentido participar nos circuítos de axuda mutua; cada casa malla o seu cereal. Para esas mallas pequenas existen, ademais do mallo, outros sistemas, como a malla ao lavadoiro, que se utilizou tamén noutras partes de Europa. Poñen unha pedra do mesmo tipo e na mesma posición que os lavadoiros de lavar a roupa e contra ela golpean os monllos, ou colocan os monllos sobre a pedra e logo golpéanos cun pau, que ben pode ser un fungueiro do carro. Ás veces en lugar da pedra usan un banco posto en posición inclinada. En Campo Lameiro baten os monllos sobre un barril cheo de auga para que non se mova. Bastantes casas fan ao lavadoiro a malluca ou malla anticipada, con fin de dispoñer de pan para invitar aos participantes na verdadeira malla.

En varias parroquias dos municipios de Cee, Dumbría e Camariñas, que contan con montes comunais nos que crían gando cabalar, mantívose ata 1935 a malla con cabalos bravos encerrados na eira e obrigados a trotar sen pausa por encima do trigo ou do centeo (Bouhier 1979: 968).

Polo tanto, no caso da malla temos distintos sistemas dependendo da data, da zona de Galicia e do nivel económico dos campesiños.

Outro exemplo de cambio de trazos culturais: a importancia da castaña na alimentación. Tamén cambiou entre o século XIX e o XX. O castiñeiro, que se supón oriúndo de Asia Menor, chegou á Península Ibérica antes da expansión romana. Críase perfectamente ben nas terras acedas das zonas húmidas e mornas. Os mellores soutos atópanse no norte, desde o navarro val de Baztán e o río Bidasoa ata Galicia. A súa decadencia comezou coa expansión do piñeiro e coa auxe da pataca, moito máis rendible, e acelerouse coa chamada tinta do castiñeiro, unha praga procedente de Portugal que asolou os nosos soutos a mediados do século XIX. Entre os anos vinte e 1960, desapareceron os últimos soutos de moitos municipios da mariña coruñesa, do baixo Tambre e ría de Noia, do alto Ulla e Deza, da Terra de Montes e do baixo e medio Miño e diminuíron nas outras zonas en que aínda quedaban. En 1972, ocupaban menos do dous por cento do territorio galego, ao longo dunha banda irregular que se estende dende a zona nordeste da provincia de Pontevedra, pasando polo sur de Lugo, ata as serras orientais, entre os 300 e os 1.000 metros de altitude, aproxi- 
madamente (Miralbes 1984: 60-61; Mandianes 1991: 293; Montanari 1993: 47, 57 e 108; Fernández Prieto 1992: 33; Bouhier 1979: 626-635 e 491-492; Domínguez 1996: 242-243). Da maior parte dos antigos soutos non quedan máis cós rastros, abondosos, na toponimia: Souto, Soutolongo, Soutelo, Souteliño, Castañeda, Castiñeira, Castiñeiriño... (Fraguas 1957: 444).

A permanencia do consumo de castañas, o que supoñía secalas no canizo, influíu nun tipo de casas que se construíu tamén entre séculos. No século XIX, empezan a ser normais as casas de dúas plantas. Pero en zonas onde o cultivo da castaña é relativamente importante, a casa de dúas plantas adáptase para secala (en zonas de intenso cultivo de castaña normalmente posuían un sequeiro como dependencia á parte). En Bamiro, concello de Vimianzo, as vivendas construídas na primeira metade do XIX teñen o sobrado só sobre as cortes, non sobre a cociña. A partir de 1850, denotando que o cultivo da castaña xa perdera forza, contan xa con dúas plantas completas e faiado (Lema 1977: 39, 45 e 61-62).

En Monfero a evolución parece ser máis lenta. Ata 1920 case todas as casas tiñan sobrado. A planta baixa estaba ocupada pola cociña e a corte. A unha altura de dous metros sobre a corte, sobre trabes que apoian na parede ou en esteos de madeira, vai o sobrado, un piso de táboas onde están o comedor dos banquetes, os leitos, os baúis da roupa e as huchas do gran. O espazo queda cerrado polas tres paredes exteriores da casa e por unha parede interior que separa a cociña da corte. Só ocupa o espazo sobre a corte, porque a lareira carece de cheminea, e carece dela probablemente porque o afumado das castañas segue sendo primordial.

Así pois, hai que ter en conta que os trazos culturais cambian segundo a época, e cada trazo ten a súa propia historia.

\section{O HÓRREO}

En Galicia existen zonas sen hórreos e zonas con hórreos. Onde hai hórreos, o seu tipo varía: en canto aos materiais, hai hórreos de corres ou cabaceiros, hai hórreos de pedra, e hórreos de madeira e mixtos; en canto á forma, hai hórreos rectangulares e hórreos cadrados de tipo asturiano. Combinando eses elementos, e outros, xorde unha gran variedade de tipos. En moitos casos existe un tipo de hórreo propio 
de cada zona. Pero non todos os tipos van unidos a unha determinada zona xeográfica. O cabaceiro, por exemplo.

O hórreo, aínda que hai algún modelo que se emprega como despensa, é, polo xeral, unha construción destinada a gardar e secar as espigas de millo. Certo que os hórreos existían antes da introdución do millo. A máis antiga representación gráfica do hórreo aparece nas Cantigas de Santa María de Afonso X o Sabio, se ben as súas paredes carecían das aberturas de ventilación (Martínez 1975), o que resulta bastante lóxico porque non estaba destinado ao millo -planta americana-, que se recolle antes de secar completamente e que necesita ser almacenado nun lugar ben ventilado. Coa introdución do cultivo do millo, que produce grandes colleitas dunhas espigas que aínda deben secar, houbo que adaptalo, incrementándoo no seu sentido lonxitudinal e dotándoo dun sistema de ventilación.

Nas comarcas en que cultivan pouco millo, os hórreos diminúen de tamaño ou son substituídos por outras formas de secado e almacenaxe (Lorenzo 1979: 110). Así, en Velle, en Moreiras e noutras aldeas e vilas ourensás con escaso millo, secan as espigas en restras nos corredores ou nas solainas (López 1936: 98-101 e 130, Ramón 1983: 154, Alonso 1983: 50). Nalgunhas parroquias, como Combarro, con abundante produción de millo e con hórreos vense, porén, solainas con espigas a secar (Martínez 1975: 293). Pertencen a casas que ou ben carecen de hórreo ou ben utilizan a solaina como lugar complementario porque collen gran cantidade de gran.

O hórreo cumpre varias funcións. Por un lado, illa os alimentos do chan evitando que a humidade os apodrente. Por iso son propios da España húmida, mentres que na zona mediterránea almacenan en silos e en pozos (Domingo 1989: 82). É esta unha función que xa cumprían os hórreos anteriores á introdución do millo e que cumpren, así mesmo, os actuais non dedicados a gardar ese cereal. Tamén relacionados coa chuvia están eses grandes beirís dos hórreos, que impiden que se mollen as paredes e o gran (Martínez 1975: 42).

Pero ademais de preservado da humidade, o millo debe ser secado, porque en Galicia non completa a maduración na leira. Para evitar que o pillen as chuvias do outono, os labregos recólleno cando aínda mantén un elevado grao de humidade, polo que resulta indispensable completar o seu secado (Martínez 1975: 37). Unha colleita pequena cabe secala 
na solaina ou no exterior dos hórreos de tipo asturiano -que son despensas propias de rexións húmidas-, pero colleitas grandes precisan secadoiros tamén grandes dotados dun sistema de ventilación. Os hórreos permiten almacenar moito millo sen necesidade de secalo previamente ao sol.

Os dous inimigos da conservación do gran son a temperatura elevada e a humidade. Evítanse por medio da ventilación e a almacenaxe do millo en espiga. A temperatura do gran sobe se non o removen con certa frecuencia, para o que resulta máis cómodo mantelo na espiga que debullado (Martínez 1975: 39).

A ventilación é fundamental. Por iso sempre teñen aberturas polas que penetra o aire e seca as espigas. E por iso nunca son construcións adxectivas e prefiren situalos en lugares abertos ás correntes de aire (Martínez 1975: 42). Nas zonas de elevada produción de millo e con aldeas e vilas concentradas, onde as casas se apiñan e non deixan espazos ventilados para o hórreo, é frecuente que busquen un sitio aberto e ben aireado fóra do núcleo, ben un camiño ancho, ben, nas vilas da costa, a ribeira. Así xurdiron as grandes concentracións de hórreos, como os de Combarro, de Redondela e de Betanzos (Martínez 1975: 49 e 292, Llano 1981: II 311, Ramón 1983: 155).

Para facilitar a ventilación é polo que os hórreos son de planta rectangular moi alongada e estreita. En canto á súa orientación, o ideal é que un dos lados menores - penais- encare o punto de onde chegan as chuvias e que o lado maior estea cara aos ventos máis secos. Pero ese ideal non sempre se consegue. Os hórreos tamén deben impedir o ataque dos ratos e das aves. Aos roedores córtanlles o paso cos tornarratos; ás aves, coidando que as aberturas de ventilación sexan estreitas.

Existen moitos tipos de hórreos dependendo dos materiais e da función que cumpren, que, á súa vez, depende da cantidade da colleita de millo. O hórreo de aspecto máis primitivo é o hórreocesto de varas ou ramas entretecidas. O seus nomes locais aluden á técnica de cestería utilizada na súa construción -canastro, canasto, canizo, cainzo, cabaz, cabazo, cabaceiro-, ao material de que están ou estaban feitos -piorno, palleiro, palleira, vergueiro, hórreo de corres- ou á forma e aspecto -cabana, cabozo-. Son hórreos de materiais e de construción baratos, de planta rectangular ou redonda, aos que, por simplificar, chamaremos cabaceiro e cabazo respectivamente. 


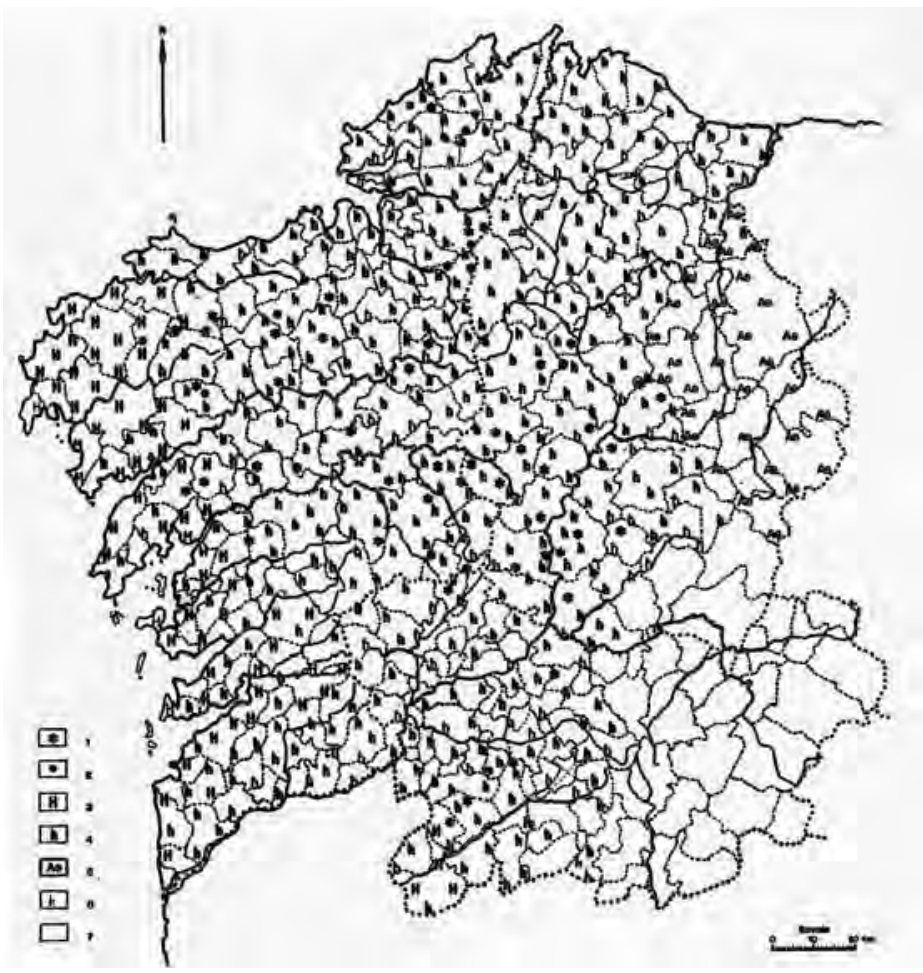

Mapa 1 (tomado de Bouhier 2001: 532). Os diferentes tipos de hórreos e a súa distribución: (1) hórreos primitivos de pólas trenzadas e de forma troncónica, (2) hórreos primitivos de pólas trenzadas e de forma rectangular, (3) hórreos rectangulares chamados de tipo galego, construídos por enteiro en cachotes ou de lastras de granito ben aparelladas, (4) hórreos igualmente de tipo galego, pero dos que a caixa está feita, parcial ou totalmente, de táboas de madeira, (5) hórreos de tipo asturiano, (6) hórreos que desaparecen no decurso dos últimos 20 a 25 anos e (7) ausencia de hórreos.

O cabazo mide 1,5 metros de diámetro e algo máis de altura. As paredes curvas adáptanse ben ao labor de cestería. A base, similar á dos hórreos típicos pero máis rudimentaria, vai apoiada en postes bastos de pedra ou madeira, sobre muros ou sobre un zócolo de cachotes. Cando apoia en catro pés, leva sobre estes un bastidor ou grade na que descansa o cesto. As rateiras consisten en láminas de lousa ou faltan. Tápano cunha cuberta cónica de colmo, moi lixeira porque o cabazo 
non leva porta e é preciso levantarlle o teito, que é móbil, para meter as espigas; para sacalas, contan cun poxigo de descarga na parte inferior. A ventilación efectúase polos numerosos buracos que deixan as varas entretecidas por todo o corpo do cesto. É propio de zonas altas e frescas con escasa produción de millo, sendo máis frecuente entre Lalín, Chantada, Taboada, Monterroso, Guntín, Palas, Melide e Arzúa (Martínez 1975: 171-174; Bas 1983: 96, Lorenzo 1979: 124-126). Pero tamén aparecen esporadicamente nas zonas de millo, ben en casas con colleita pobre e sen hórreo, ben en casas con hórreo para gardar os excedentes de anadas especialmente abondosas (Bas 1983: 96-99; Llano 1981: II 294-297; Bouhier 1979: 1291; Fernández de Rota 59-60).

O cabaceiro, de planta rectangular, alongada e estreita, ten, por estar tecido en corres, as esquinas redondeadas. Atópase en lugares moi dispersos (Martínez 1975: 174-175).

O hórreo de tipo asturiano aparece na zona oriental da provincia de Lugo, no límite coas provincias de Asturias e León, asociado coas pallozas. Apóiase sobre esteos de madeira troncopiramidais de base cadrada, sobre os que van tornarratos circulares de lousa. A planta, duns $25 \mathrm{~m}^{2}$, é cadrada, o que demostra claramente que non está pensado para secar millo no interior. $\mathrm{O}$ mesmo demostra o feito de que entre as táboas das paredes non queden aberturas de ventilación. En efecto, nesa zona o pouco millo cultivado sécano na parte exterior do hórreo, no corredor, da mesma forma que nas soleiras e corredores das casas doutras comarcas. Gardan o millo dentro unha vez que está seco, igual que gardan a carne, os queixos e as patacas. Digamos que é unha despensa de zona chuviosa na que apenas se cultiva millo. No espazo debaixo do hórreo tipo asturiano gardan leña, o carro ou os apeiros de labranza. Os máis antigos aínda en uso foron construídos na segunda metade do XVIII; os últimos, na década dos cincuenta (Martínez 1975: 107-108 e 131-132; Llano 1981: II 301; González Pérez 1991: 29 e 226).

O hórreo máis abundante, o máis típico, o propio de lugares e casas con importante colleita de millo, está formado por unha caixa prismática sobre catro ou seis pés de pedra con capitel redondo -o tornarratos- tamén de pedra, que impide que os roedores cheguen ao gran, ou sobre dous, tres ou máis muros transversais -cepas-. Ás veces cerran con muros de cachotes o espazo que queda baixo a cámara formando 
dese xeito unha nova dependencia, o celeiro, onde gardan patacas e outros produtos agrícolas.

A lonxitude do hórreo, moi variable, depende da cantidade de millo recollido. Normalmente miden de 4 a 5 metros de longo e 2,50 de alto. Os máis longos son os de Lira-Carnota, de 36,55 metros, o de Araño-Rianxo, de $34,80 \mathrm{~m}$ e o de Carnota, de $34,70 \mathrm{~m}$. Non obstante, a anchura mantense entre 1,3 e 1,5 metros, co obxecto de que as espigas non estean nunca demasiado afastadas das paredes laterais -os costais- e o millo seque mellor (Lorenzo 1979: 112-113). No interior colocan as espigas ordenadamente, en sectores separados por tabiques transversais de táboas, asegurando así a súa boa ventilación e que non se escangallen (Martínez 1975: 130 e 115).

Hai hórreos secadoiro de millo, que na comarca de Lalín chaman bórreas, máis anchos que o típico. Nestas hórreas o espazo interior queda dividido en tres partes lonxitudinais: as dúas contiguas aos costais, estreitas e mellor ventiladas, son utilizadas para secar as espigas; e a parte central, para a circulación das cestas (Martínez 1975: 115). Ademais, estas hórreas, como os hórreos asturianos, úsanse como despensa para carne, queixos, etc.

Como materiais de construción empregan con preferencia os que ofrece o medio circundante e custan menos. Claro que, como sucede coas casas, unha familia rica pode optar por materiais máis caros dos que se usan correntemente na súa zona. E unha familia pobre contentarase cun hórreo de madeira onde a maioría elixe a pedra (Martínez 1975: 39 e 48; Lorenzo 1979: 113).

Os hórreos antigos foron construídos en pedra nas zonas de boas canteiras e en madeira ou madeira e pedra nas zonas de pedra cativa. En cambio, os construídos durante o período 1926-1965 son preferentemente de tixolo, que resulta máis barato que a pedra e non podrece como a madeira.

Hai, pois, hórreos de pedra, de madeira, mixtos e de tixolo. O material das cubertas é, dependendo da zona, o mesmo que o das casas (Martínez 1975: 134 ss.). A preferencia pola pedra fronte á madeira nun país tan chuvioso como o noso non precisa explicación. Si, en cambio, o feito de que os hórreos completamente de pedra e os mixtos con moita pedra aparezan no oeste e no sur. Pois ben, esa zona caracterízase por un granito excelente, sen fisuras, que permite o corte de pedras 
de boas dimensións e perfectamente talladas. É a mesma zona onde as casas son de cantería e onde ata son de granito os esteos das viñas (Martínez 1975: 43, 46-48 e 235 ss.).

O que non resulta doado é facer na pedra as aberturas de ventilación da cámara. A solución máis rudimentaria, que só se atopa nalgúns hórreos do oeste da Coruña, pouco eficaces no secado do millo, consiste en aberturas irregulares e asimétricas obtidas por simple separación dos cachotes das paredes. Os hórreos de pedra tallada imitan o enreixado das paredes de madeira: os costais van cerrados con prismas de pedra separados un ou dous centímetros, deixando entre eles aberturas verticais. Nun tipo máis elaborado déixanse aberturas horizontais, ben rebaixando a parte inferior de cada pedra, ben separando fiadas superpostas por medio de pequenas pezas de pedra ou porcións de morteiro (Martínez 1975: 132-133; Llano 1981: II 307).

Os hórreos de pedra apoian sobre esteos tamén de pedra. Son posibles porque a calidade da rocha o permite, e preferibles porque garanten un mellor illamento do chan que as cepas ou o celeiro (Martínez 1975: 43, 45, 120, 127 e 129). O seu número, que non pode ser menos de catro varía, evidentemente, coa lonxitude do hórreo. A separación entre esteos vén dada pola lonxitude das trabes, que á súa vez depende da calidade da pedra da zona. Así, na provincia de Pontevedra, con granito de excelente calidade, a separación aumenta. O tornarratos é unha pedra plana que se coloca sobre os pés a xeito de gran capitel para impedir que os ratos accedan á cámara.

Os hórreos mixtos, os máis abundantes, combinan pedra e madeira en distintas proporcións. É bastante común que os elementos de pedra sexan os apoios e os penais (Martínez 1975: 208 ss.; Llano 1981: II 304 ss.).

Os hórreos de madeira ou mixtos con pouca pedra son propios de zonas de pedra de mala calidade, inadecuada para o tallado, e correspóndense, polo tanto, coas casas construídas de cachotes. O contraste entre as comarcas situadas ao leste e as situadas ao oeste da ría da Coruña e o río Mero demostra claramente a relación entre as posibilidades que ofrece a pedra da zona e o material dos hórreos. Ao leste o hórreo é totalmente de madeira; ao oeste é totalmente de pedra. Non se trata dun capricho, non obstante. Examinando o mapa xeolóxico -escribe Martínez Rodríguez-atopamos unha liña que segue o eixe da ría e o val 
do Mero e que divide a zona granítica do oeste da zona xistosa do leste (Martínez 1975: 43, 46-48 e 180 ss.; Llano 1981: II 299).

Nos hórreos de madeira e mixtos as táboas dos costais - doelas- forman unha celosía que asegura a ventilación da cámara. Están dispostas unhas paralelas ás outras, deixando no medio unha abertura o suficientemente estreita que lles impida aos paxaros comer o gran do interior (Martínez 1975: 132).

Os hórreos de madeira, mixtos e de tixolo adoitan levar, en lugar de pés de pedra, cepas - muros de sostén dispostos de forma transversal- ou un muro continuo en todo o contorno da cámara que cerra un espazo chamado celeiro. Esa correspondencia é de todo lóxica, pois os hórreos de madeira aparecen precisamente nas zonas con pedra de mala calidade inservible para tallar esteos (Martínez 1975: 43, 45, 122 e 128-129). Os hórreos pequenos apóianse, ás veces, sobre dúas cepas, situadas nos penais, pero máis frecuentemente sobre tres, a terceira na parte central.

Nos hórreos sobre cepas, a rateira, grande e rectangular, normalmente dunha soa peza, cobre a totalidade da cepa sobresaíndo polos seus catro costados. Nos hórreos sobre celeiro actúa de tornarratos un saliente continuo entre a base e a cámara. Se o piso da cámara é de pedra, forman o saliente as lousas do contorno que sobresaen un pouco (Martínez 1975: 123).

Os de tixolo, que respectan as medidas e formas tradicionais, aparecen nos anos vinte e trinta, cando ese material empeza a ser común na construción (Martínez 1975: 159 e 279; Lorenzo 1979: 117). Neles a cámara é completamente de tixolo; as cepas ou o celeiro, ben de tixolo, ben de cachotes (Martínez 1975: 122). Tamén utilizan tixolo para substituír nos hórreos mixtos as paredes de madeira deterioradas. Por esta razón, os hórreos de tixolo abundan máis nas zonas con tradición de hórreos mixtos; nas zonas de hórreos de pedra estes, mellor conservados, non tiveron que ser reconstruídos, pero os novos tamén os fixeron de tixolo (Martínez 1975: 133-134 e 150).

Para asegurar a ventilación, empregan diversos sistemas: colocan os tixolos transversalmente deixando os seus buracos como aberturas de ventilación, deixan nas fiadas de tixolos ocos ben distribuídos, usan tixolos especiais para formar verdadeiras celosías, ou substitúen as doelas de madeira por barrotes de cemento (Martínez 1975: 279; Lorenzo 1979: 117). 


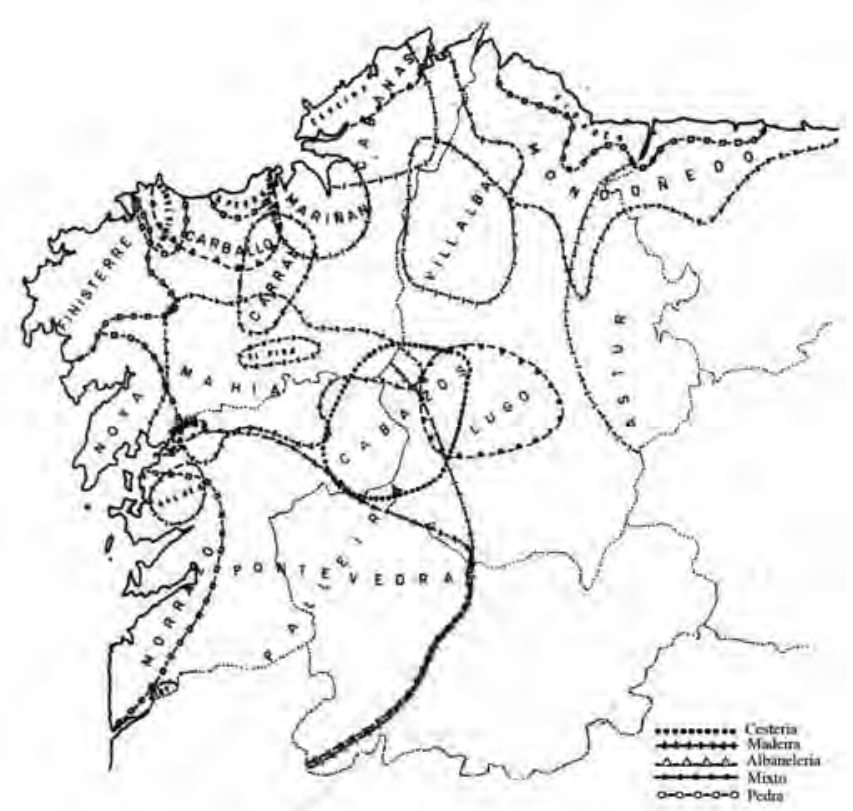

Mapa 2 (tomado de Bouhier 2001:149). Material co que están construídos os hórreos.

\section{A HERDANZA}

En toda Europa hai zonas de herdanza igualitaria e de mellora en diversos graos (Segalen 1992: 75-76). O Código Civil español establece uns límites máximos para a mellora, co fin de defender os intereses dos fillos non mellorados. Ese límite está nos dous terzos, quedando o terzo restante para repartir entre todos os irmáns. Quede claro que a lei establece límites máximos: nada impide ao testador repartir as súas propiedades a partes iguais entre todos os fillos. De feito, tanto a mellora forte coma a herdanza igualitaria son prácticas habituais nalgunhas zonas de Galicia, e entre eses dous extremos cabe un amplo abano de posicións intermedias (Bouhier 1979: 1088; González Reboredo 1990: 60).

A lexítima, xusta porque vela polos dereitos dos non mellorados, ten o inconveniente de desmembrar a explotación. Para evitalo, recorren 
a diversos procedementos. Un, bastante minoritario, pero presente en moitas parroquias, se ben está máis documentado na Estrada, consiste no matrimonio por troque: un mozo e unha moza dunha casa contraen matrimonio cunha moza e un mozo doutra, renunciando as mulleres a recibir a lexítima na casa paterna a cambio de recibila na casa dos seus sogros. Esta solución está especialmente indicada para casas con só un fillo e unha filla; desa forma o matrimonio novo herda a explotación paterna completa (García 1989: 21).

Existe un truco, e algúns utilízano, para burlar a lei e deixarlle ao mellorado máis do que legalmente lle correspondería. Consiste en pasar por venda: os pais simulan vender os seus bens a un dos fillos, que queda con todo. Este procedemento é perigoso para o patrucio porque renuncia á arma coa que conta para asegurarse o coidado dos fillos na súa vellez. Abundan os contos e refráns que alertan dese perigo. Un exemplo: «O que dá o que ten antes de que morra merece que lle dean cunha cachiporra» (Carreras 1980: II 786; Lisón 1971b: 235).

Segundo as zonas, atopamos mellora masculina, mellora feminina e herdanza igualitaria; nalgunhas zonas de Ourense existe, ademais, a congrua, que é a herdanza igualitaria en vida.

\subsection{A mellora patrilineal}

En boa parte do país queda coa mellora, preferentemente, o fillo varón máis vello, que recibe o significativo nome de vinculeiro, ou sexa, o que establece o vínculo entre dúas xeracións. Ás mulleres tócalles a mellora cando non hai homes, ou cando os pais os descartan por algunha razón. Cabe a posibilidade de que un pai lle deixe a mellora dos seus bens a un fillo e que a súa muller lla deixe, dos seus, a outro distinto, pero na práctica ambos os esposos adoitan elixir o mesmo mellorado.

Como sucede noutras partes de Europa, as melloras máis fortes danse na zona de montaña (Segalen 1992: 75). Nas montañas orientais de Lugo e Ourense e nas súas inmediacións a manda forte para o fillo varón máis vello é a norma. Normalmente recibe as dúas terceiras partes dos bens, entrando tamén a participar cos demais irmáns no terzo restante, que se divide a partes iguais. No caso de que o primoxénito 
non poida ou non queira ser o herdeiro, elixen outro dos fillos varóns; se non hai varóns, herda a filla máis vella (Lisón 1971b: 175-176, 194 e 346; González Reboredo 1990: 59 e 61; Rodríguez Campos 1990: 140 e 155-157; Tenorio 1982: 87-93).

Tamén acostuman a mellorar cos dous terzos en Coristanco, Fruime e Negrelos; en Melide, co terzo e quinto. Na Terra Chá, o mellorado recibe a casa con todas as súas pertenzas mais o circundo ou terras que a rodean. Por Monforte de Lemos, a mellora, algo menor, adoita ser dun terzo. Tamén é dun terzo en Monfero, Pontedeume, Vilamaior e Outes (Lisón 1971b: 176-178; Fernández de Rota 1984: 52; Risco 1979a: 404; Sixirei 1982: 141).

$\mathrm{Na}$ montaña lucense o grao de cumprimento da norma hereditaria preferente é moi alto. Outorgan mellora no 92,6\% dos casos. As partillas igualitarias, só o 7,2\%, corresponden a casas nas que, como veremos logo, a mellora non xoga un papel decisivo. O mellorado é o fillo máis vello no $59,2 \%$ dos casos, un segundón no $7,2 \%$, e unha muller no $28,3 \%$. Herda un segundón se o primoxénito emigra, se casa cunha vinculeira de mellor posición -e vai vivir con ela- ou se casa cunha muller que non é do agrado dos pais. Herda unha filla cando non hai varóns ou son física ou mentalmente incapacitados; cando, no momento da morte do pai, os varóns son aínda demasiado novos; cando os varóns emigran; cando o único varón casa cunha vinculeira máis rica; e cando os homes non cumpren cos requisitos esixidos. Ás veces unha filla consegue con cariño e garatuxas romper a norma e ser mellorada, aproveitando, por exemplo, que os pais non conxenian ben co fillo varón (Lisón 1971b: 203; González Reboredo 1990: 59; Iturra 1988: 109).

Os requisitos fundamentais para recibir a mellora, ademais de gozar de saúde mental e física, son coñecer a terra, saber traballala e ser un traballador honrado, o que equivale a ser frugal e laborioso.

O vinculeiro, a cambio do privilexio que se lle concede, contrae certas obrigas: coidar os pais mentres vivan e os irmáns mentres permanezan solteiros na casa, especialmente os desvalidos, e pagar o enterro dos pais e os gastos da transmisión dos bens. En realidade son precisamente esas as razóns coas que os propios interesados xustifican a mellora. Considérana como unha recompensa polos coidados que, como fillos de bendición, tiveron cos pais na súa vellez. Vena, pois, como un seguro para a vellez. Incluso nas zonas de partillas igualitarias 
un dos fillos, en pago ás atencións cos pais, pode herdar, a maiores, a casa paterna ou recibir outro tipo de compensación.

Se non existise unha norma que favorece case automaticamente a un dos fillos, multiplicaríanse as tensión entre os irmáns. Pero como esa norma non é totalmente fixa e inmutable, depende da decisión dos pais, cabe a posibilidade de manipulación, o que fai da herdanza algo vivo e moitas veces tenso.

Pero a compensación polos coidados aos pais non é o único motivo, nin o máis importante, da mellora. O propio feito de que unha certa compensación apareza tamén na zona de herdanza igualitaria demostra que para que exista mellora entran en xogo outros factores. En primeiro lugar, cómpre analizar a preferencia polo varón máis vello. A elección dun home parece relacionada co feito de que a agricultura con arado está sempre en mans dos varóns; nas comunidades mariñeiras reciben a mellora as mulleres precisamente porque a agricultura non é a actividade económica básica. O primoxénito ten unha vantaxe: garante que a explotación quede, na vellez dos pais, a cargo dun adulto; se, por exemplo, herdase o máis novo, en bastantes casos sería aínda un neno incapaz de gobernar a casa cando o patrucio xa fose ancián.

Unha poderosa razón para a mellora, que os propios interesados tamén sinalan, é a de non desmembrar a casa. A maioría das explotacións, próximas ao tamaño mínimo indispensable para posibilitar o que se considera unha vida digna, deben ser legadas case na súa totalidade a un dos fillos. Postos a elixir entre a supervivencia dunha familia ou a fame para todos, con bo criterio, elixen a primeira opción. Como di un refrán, «bens divididos, bens perdidos». En El bosque animado, Fernández Flórez debuxa esta caricatura do repartimento entre os irmáns de Fiz de Cotobade: «Quedoulles un prado tan repartido que se unha vaca ía pacer nel, non podía comer a herba propia sen ter as patas traseiras na propiedade do irmán e os cornos proxectando a súa sombra na dun terceiro».

A perda de terras correspondente á lexítima esperan compensala coas que achega a esposa, da súa lexítima, e, se é posible, comprándolles a súa parte aos outros irmáns. Por outra banda, o vinculeiro, para retardar o momento de desprenderse de parte da explotación, adoita dilatar todo o posible as partillas (Sotelo 1993: 319-320). Ademais, como os segundóns rara vez se independizan como labregos, sendo o normal que queden 
solteiros na casa ou emigren, as súas terras quedan a disposición da casa; cando os solteiróns da casa morren, as súas terras reincorpóranse legalmente á explotación -da que, de feito, nunca se separaron.

Os datos históricos confirman a función da mellora como medio de frear a mingua das explotacións por debaixo do límite da supervivencia. Cando no século XVIII a superficie mínima indispensable baixou debido ao incremento da produtividade conseguida grazas aos novos cultivos e aos avances técnicos, o número das explotacións aumentou sen que a mellora, que xa era práctica no século XVI, o impedise (Miralbes 1984: 225; Saavedra 1992: 146-147).

A razón de supervivencia é tan poderosa que incluso cando un pai morre sen testar, os irmáns recoñecen o dereito do primoxénito a quedar coa mellora. Naturalmente, danse casos nos que un dos irmáns, en contra desa norma e apoiado na falta de testamento, se nega a recoñecer ese dereito.

Por suposto, a mellora, como calquera outra institución humana, non é eficaz ao cen por cen. Explotacións grandes fragméntanse e casas de renome veñen a menos e incluso chegan a desaparecer, porque na permanencia do patrimonio interveñen máis factores, como a sorte, a laboriosidade dos integrantes e acerto nas alianzas.

As casas ricas poderían repartir os bens igualitariamente entre os irmáns, pero iso supoñería renunciar á súa privilexiada posición. Por contra, os pobres non fan mellora, pois non teñen explotación viable ou prestixio que salvar; a pobreza pode ser repartida a partes iguais (Lisón 1971b: 201-202).

As opcións que se lles presentan aos desherdados son casar e levar unha vida de pobres caseteiros, traballando ao xornal ou practicando algún oficio, permanecer solteiros na casa ou emigrar. Non obstante, é inexacta, por esaxerada, esa imaxe dun fillo beneficiado e un montón de irmáns condenados á pobreza ou á emigración. Porque, en contra dun tópico moi estendido, as familias non chegan aos tres fillos de media. Tendo en conta que un recibe a mellora e que unha moza casa cun vinculeiro doutra casa, a porcentaxe de desherdados non é excesivamente alta; o sistema incorpóraos, con máis ou menos problemas, como xornaleiros e artesáns. Optan pola emigración cando un determinado lugar, como Arxentina nos anos vinte ou Europa nos sesenta, lles ofrece mellores perspectivas que as que esperan quedando na propia 
parroquia. Incluso o vinculeiro dunha casa pobre ou mediana pode renunciar á mellora, como sucedeu bastante a miúdo nos anos sesenta, se a emigración lle ofrece expectativas máis atraentes que o traballo no campo. Neses casos, os pais déixanlle a mellora ao fillo ou filla que desexa quedar na casa (Lisón 1971b: 185, 198 e 354; Bouhier 1979: 1090).

É lóxico que a montaña lucense, zona das melloras máis fortes, sexa tamén a das casas con maior número de membros. Como as terras son menos produtivas, as explotacións aumentan de tamaño e requiren máis forza de traballo, o que obriga as familias a ter máis fillos. Pero esa solución -está claro- non serviría de nada se eses fillos se repartisen o patrimonio a partes iguais, e tampouco serviría de moito se a mellora fose débil e os fillos segundóns recibisen partes grandes. Sendo unha mellora forte, a lexítima que lles corresponde a cada un dos numerosos irmáns é tan pequena que os forza a quedar solteiros na casa, achegando así a forza de traballo necesaria e ademais deixando, á súa morte, as súas terras de novo á casa (Bouhier 1979: 1089; Saavedra 1992: 121-122 e 144).

Ligado á mellora está o dote que reciben as mulleres ao casaren para outra casa. O dote é un adianto da lexítima como axuda no momento de fundar unha nova familia e como compensación por quedar exclú́das da mellora. A contía depende das necesidades do novo matrimonio e, sobre todo, das posibilidades dos pais (Iturra 1988: 115). En zona de herdanza igualitaria non ten razón de ser (Bermejo 1989: 114-116), pero acada un valor considerable nas comarcas de mellora forte; por exemplo, na montaña lucense, onde o costume de dotar estivo vixente durante todo o período 1926-1965, consiste nun prado ou nunha cantidade nada desprezable de diñeiro. A título de orientación damos o valor do dote en cartos ofrecido polas casas ricas (González Reboredo 1990: 39; Lisón 1976: 188):

\begin{tabular}{|c|r|r|r|r|r|}
\hline Ano & 1920 & 1930 & 1950 & 1960 & 1974 \\
\hline Pesetas & 1.000 & 5.000 & 50.000 & 100.000 & 400.000 \\
\hline
\end{tabular}

O dote contribúe a que as fillas contraian matrimonio con vinculeiros de casas homólogas ou incluso máis fortes. Sen dote, a filla dun rico non sería de forma inmediata -si no momento de facer as partillas- mellor partido que a filla dun pobre. Para conseguir que a filla case para unha casa forte, o seu pai debe dotala xenerosamente. E, desde o punto de vista da casa do noivo, canto maior sexa o dote que achegue 
a futura esposa, menos se notará o recorte no tamaño da explotación debido ás lexítimas. Nos casos nos que se pretende casar un varón cunha vinculeira, tamén é dotado (Lisón 1976: 180).

Para que se saiba con certeza o dote que acompañará á moza, os pais fan unha oferta. Entran directamente en tratos coa casa, ou casas, na que queren acomodar a filla, ou deixan correr a voz do que ofrecen. Ás veces, sobre todo se os posibles noivos viven en aldeas distantes e non resulta fácil un noivado ao uso, os pais encargan as conversas a un chufón, que ten por cometido chufar, ou sexa, eloxiar os méritos da persoa á que representa (Lisón 1976: 166-190).

Son numerosas as cantigas nas que, con bo humor, as mozas se queixan de que, despois de logrado o matrimonio, os pais non cumpren co dote prometido (Blanco 1992: n 21; Lorenzo 1973: n 1339. Tamén Blanco 1992: no 212, 722 e 2898; Lorenzo 1973: no 2481 e 1332-1338):

$\begin{array}{ll}\text { Miña nai por me casar } & \text { Miña nai por me casar } \\ \text { prometeume canto tiña; } & \text { prometeume unha xugada; } \\ \text { cando foi a darme o dote, } & \text { desque casada me viu } \\ \text { pagoume cunha galiña. } & \text { non ma deu a condanada. }\end{array}$

\subsection{A mellora matrilineal}

Nas comunidades mariñeiras e nalgunhas zonas labregas de forte emigración, as normas sobre a mellora non son tan ríxidas. Normalmente, recíbea unha filla, preferentemente a máis nova, pero abundan as excepcións. A mellora case sempre consiste na casa e, ás veces, o barco ou algunha leira; o resto divídeno a partes iguais (Lisón 1971b: 178-180, 244 e 347). É, pois, unha mellora débil.

Os interesados xustifican a preferencia polas mulleres con diversos argumentos. Din que convén favorecer as fillas porque os homes ábrense camiño na vida máis facilmente. Din tamén que as fillas, máis cariñosas que os fillos e, por suposto, que as noras, coidarán mellor os pais na súa vellez, algo co que probabelmente tamén están de acordo os labregos da zona de mellora forte, pero as circunstancias obríganos a renunciar ás fillas. Precisamente porque nas parroquias con manda matrilineal preferente xoga un papel destacado a relación persoal cos pais é polo que as normas non son tan ríxidas. Un pai non dubidará 
demasiado en mellorar calquera das fillas, non necesariamente a máis nova, ou incluso un fillo, se as relacións son mellores que coa candidata preferente. Coa mellora compensará os coidados recibidos.

Un terceiro argumento é que a filla transmite a liñaxe con maior fiabilidade:

$$
\begin{aligned}
& \text { Os fillos da miña filla } \\
& \text { todos meus netiños son; } \\
& \text { os fillos da miña nora } \\
& \text { quizais si, ou quizais non. } \\
& \qquad \quad \text { [Lisón 1971b: 256] }
\end{aligned}
$$

A razón ética -ou sexa, a razón da que non son conscientes os interesados- é que ao non ser a agricultura a actividade económica básica nada forza a preferencia polos varóns. Nas parroquias labregas con forte emigración, que é fundamentalmente masculina, resulta lóxico que herden as mulleres, que son as que se encargan dos traballos no campo e serán tamén as que coiden os pais. Ademais, se a residencia fose patrilocal, as mulleres dos emigrados pasarían boa parte da súa vida cos sogros sen a presenza mediadora do marido.

Algo similar ocorre nas comunidades mariñeiras. Se tras o matrimonio as esposas acompañasen os maridos ás súas casas, terían que convivir coas sogras sen o home durante os meses que eles botan na pesca de altura; e peor aínda se o esposo falece nun dos frecuentes naufraxios. A viúva, sexa de vivo ou de morto, estará mellor na casa de seus pais (Lisón 1971b: 347 ss.). ¿Por que se prefire a filla máis nova? Porque desa forma evítase que o esposo conviva coas súas cuñadas máis novas.

\subsection{As partillas igualitarias}

Nalgunhas zonas os pais reparten as súas propiedades a partes iguais entre todos os fillos e fillas. Unhas veces os fillos reciben a súa parte - mera- despois da morte dos pais, outras recíbena en vida. Neste caso, que se dá nos concellos de Lobios, Baltar, Entrimo e Calvos de Randín, os herdeiros deben garantir a subsistencia dos seus proxenitores. Os pais anciáns viven sós, ou cos fillos solteiros, ou con algún fillo ou filla casados, ou con varios deles por rolda, pero en calquera destes casos reciben de todos os fillos unha renda para atender as súas necesidades, 
a congrua ${ }^{1}$. Fíxana nunhas determinadas cantidades de millo, patacas, fabas, porco e carros de leña proporcionais á herdanza. Se algún fillo non cumpre, corre o risco de ser desherdado, pois a transmisión legal dos bens faise no testamento.

A casa paterna repártena tamén a partes iguais. Se é grande, poden dividila en varias vivendas; se é pequena, táxana e un dos fillos -normalmente, algún que non dispón de vivenda en propiedade- queda con ela pagándolles aos irmáns o que lles corresponda. Reparten tamén as vacas, porcos, pitas, ovellas, mantas, sabas, pratos e demais útiles domésticos (Lisón 1971b: 182, 306-310 e 319; Ramón 1983: 135; Mandianes 1984: 93). Este desexo de igualdade non impide que os pais melloren lixeiramente un dos fillos ou fillas, se este se encarga de forma case exclusiva de coidalos na súa vellez (Lisón 1971b: 305). Así pois, non hai separación tallante co que sucede nas zonas de mellora débil.

Os interesados valoran a herdanza igualitaria como máis xusta que a mellora, porque non establece diferenzas entre os fillos, evitando así tensións, envexas e odios entre irmáns (Lisón 1971b: 193-194), unha razón que sen dúbida entenden os labregos das comarcas de mellora, pero que a realidade lles empece ter en conta.

A herdanza igualitaria é norma maioritaria nas parroquias próximas ás cidades e tamén nunha ampla zona da provincia de Ourense. No primeiro caso trátase de parroquias nas que as terras achegan unicamente un complemento aos ingresos fundamentais da casa, que proceden do traballo asalariado (López 1936: 176).

A zona de Ourense onde rexe a norma igualitaria é unha zona pobre. Nalgúns concellos, como Castro Caldelas, Esgos, Xunqueira de Espadañedo, Nogueira de Ramuín, Paderne de Allariz, Pereiro de Aguiar e San Xoán de Río, a pobreza da agricultura forza a xente a buscar o sustento nos máis diversos oficios; é a zona dos profesionais ambulantes (Fidalgo 1992: 108; Lisón 1971b: 181). Tamén se segue a norma igualitaria en varios concellos da Limia Baixa, zona de media montaña de recursos limitados.

Un feito confirma a relación da herdanza igualitaria co papel secundario desempeñado pola agricultura: cando nos anos sesenta baixou o 1 Variantes: congria, ten₹a, renta, requia. Congrua é a pervivencia da congrua sustentatione do
dereito antigo (Lisón 1971b: 307; Mandianes 1984: 92-93). 
interese polas terras pois boa parte dos mozos e mozas prefería emigrar á cidade ou a Europa, estendeuse a herdanza igualitaria pola zona que antes era de mellora; naturalmente, algunhas explotacións, divididas, desapareceron (Iturra 1988: 112).

Así pois, a razón da herdanza igualitaria en Ourense é a mesma pola que, en zona de mellora, a fan as casas pobres: as terras son tan poucas que non achegaría ningún beneficio mantelas indivisas.

\section{A RESIDENCIA MATRIMONIAL}

$\mathrm{Na}$ Galicia da primeira metade do século Xx atopamos varias formas de residencia matrimonial: patrilocal, matrilocal, neolocal e natolocal.

Nas zonas de mellora patrilineal, o novo matrimonio vive, loxicamente, na casa do esposo, que é quen herda terras e vivenda (Risco 1979a: 404-405); xa que logo, a muller ten que abandonar a casa dos seus pais. As cantigas recollen a dor das mozas ao deixar a casa paterna para ir a outra onde son estrañas e onde estarán sometidas á vontade dos sogros.

Fóra casei: adiós porta, portiña do meu quinteiro, auga do meu saídiño, sombra do meu manzaneiro.

[Lorenzo 1973: no 1044; Blanco 1992: nº 408$]$

Unha forma de ritualizar esa pena é a tardanza en pronunciar o si. Outra, consiste en retardar varios días o traslado á casa do noivo e a consumación do matrimonio. É un costume coñecido noutras partes de Europa e que en Galicia, polo menos no período 1926-1965, está documentado en poucas parroquias. En Ourense tardan tres ou catro días en reunirse. En Viana do Bolo era costume que a noiva durmise coa madriña a noite da voda. En Celanova, antes de convivir, pasan nas súas respectivas casas oito ou quince días. En Mondoñedo a noiva pasa a noite de vodas coa madriña e o noivo co padriño. O mesmo fan en Donís, onde o costume aínda se conservaba en 1968. En Cabo de Cruz o período de continencia posmatrimonial duraba tres días (Carreras 1980: X 93; Tenorio 1982: 82; Bouza-Brey 1982: II 7-12; Risco 1979b: 566). 
A entrada da noiva na casa paterna do seu marido revístese dunha certa solemnidade. A esposa, que adoita ir a cabalo, leva unha arca co enxoval e, ás veces, regalos para os familiares do marido. Os acompañantes disparan de cando en vez as escopetas anunciando a comitiva. En Melide agarda na porta da casa a sogra cunha vela acesa na man, que entrega á noiva posta de xeonllos. Nalgúns lugares o noivo acompaña á noiva, chaman á casa dos pais e axeónllanse para recibiren a bendición paterna: «Deus vos vexa vir ben casados e vos faga ben amados» (Risco 1979a: 405-406; Lisón 1971b: 379; Fraguas 1973: 91). En Murias de Rao o acompañamento canta:

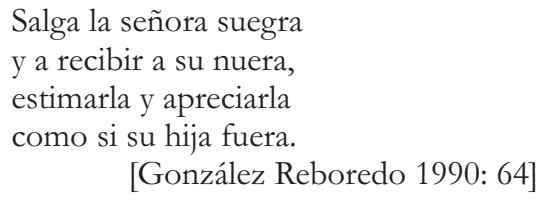

$\mathrm{Na}$ casa do noivo celebran a tornavoda. En Viana non sempre se celebraba. En Melide participan os mesmos convidados da voda. En Xavestre ten lugar ao día seguinte. En Ponte Ledesma xantan na casa da noiva e cean na do noivo. En Monfero a tornavoda é máis abundante e rica (Tenorio 1982: 82; Risco 1979a: 405; Fernández de Rota 1984: 145; Sixirei 1982: 146; Fraguas 1973: 88; Sotelo 1993: 154).

En Viana do Bolo, a principios de século, tres días despois da voda, unha comitiva de casados novos entregáballe ao esposo a caxata, un báculo de madeira que pertencía ao pobo e que gardaba en depósito o último casado. O noivo invitaba a comitiva a pan e viño e gardaba ata o seguinte casamento a caxata (Tenorio 1982: 83) como símbolo do poder do esposo sobre a muller e a familia.

Nas zonas de manda matrilineal o novo matrimonio reside preferentemente na casa paterna da noiva. Esta norma permite ás esposas dos mariñeiros, que ás veces botan varios meses fóra da casa, convivir cos seus propios pais e irmáns.

O sistema de partillas igualitarias é compatible con varios tipos de residencia: neolocal e natolocal. Chámase residencia neolocal cando o novo matrimonio vive nunha casa que non é a paterna de ningún dos dous. Nas parroquias próximas ás cidades os asalariados optan pola residencia neolocal; un dos fillos queda coa casa paterna, comprando aos demais os seus dereitos. $\mathrm{Na}$ zona de mellora a residencia neolocal é 
obrigada para os fillos segundóns que casan; é, pois, o tipo de residencia propia dos caseteiros.

Na Limia Baixa cada un dos esposos queda a vivir, durante un tempo, normalmente varios anos, na propia casa paterna; de noite, o marido vai durmir coa súa esposa á casa dos pais desta. É o que se chama residencia natolocal. Empezan a convivir en casa propia ao recibiren a herdanza, que, para non alongar a separación da parella, adoita ser en vida dos pais. Os matrimonios que quedan coa casa dos pais del ou dos pais dela deben comprarlles a súa parte aos outros irmáns.

A mesma práctica aparece noutras zonas de Europa, todas elas pobres en recursos (Lisón 1971b: 305-310; Lisón 1976: 166-167). Dáse en certas comarcas castelá-leonesas, estremeñas e andaluzas; tamén na irlandesa Tory Island, en Trás-os-Montes e en comarcas dos Pireneos franceses (O’Neill 1984: 336-337). A Limia Baixa é zona de media montaña, con escasos solos e ademais pouco produtivos. En consecuencia, hai unha baixa densidade de poboación; en 1940, a densidade era de 43,3 hab $/ \mathrm{km}^{2}$, fronte aos 85,61 do conxunto de Galicia.

Non é unha opción en principio apetecible porque obriga aos esposos a viviren separados, sen constituír unha familia, unha unidade económica. Pero, para labregos con escasos recursos, como son os da Limia Baixa, ofrece certas vantaxes. Ou polo menos evita os graves problemas que ofrecen os tipos de residencia alternativos. A residencia neolocal, en primeiro lugar, non está ao alcance destes labregos, que en moitos casos rozan a pobreza. Pola súa banda, as residencias patrilocal e matrilocal nunha zona de partillas igualitarias coma esa tamén terían un serio inconveniente: o esposo de fóra traballaría, en parte, para os seus cuñados. Quedando na casa paterna ata partir a herdanza, cada un traballa polo ben da casa da que recibirá unha parte alícuota. Nunha determinada casa todos os irmáns, casados e solteiros, traballan para a casa que herdarán a partes iguais. En cambio, con residencia matrilocal ou patrilocal, a persoa que fose vivir á casa do cónxuxe traballaría pola prosperidade dunha explotación da que nin recibirá parte nin o cónxuxe será herdeiro mellorado; os beneficiados do seu esforzo serían, pois, os cuñados, aos que lles correspondería unha parte exactamente igual que ao seu consorte.

Para que a residencia natolocal sexa razoablemente práctica, convén que as casas dos esposos non disten demasiado e que as aldeas sexan o suficientemente grandes para atopar parella. Isto sucede nesa zona de 
Ourense, de asentamentos grandes. No resto de Galicia, de asentamentos pequenos e espallados, o marido tería serias dificultades para atopar na súa aldea unha moza que non fose parente; e se casase cunha moza doutra aldea, moi probabelmente se vería obrigado a longos desprazamentos diarios para durmir coa esposa.

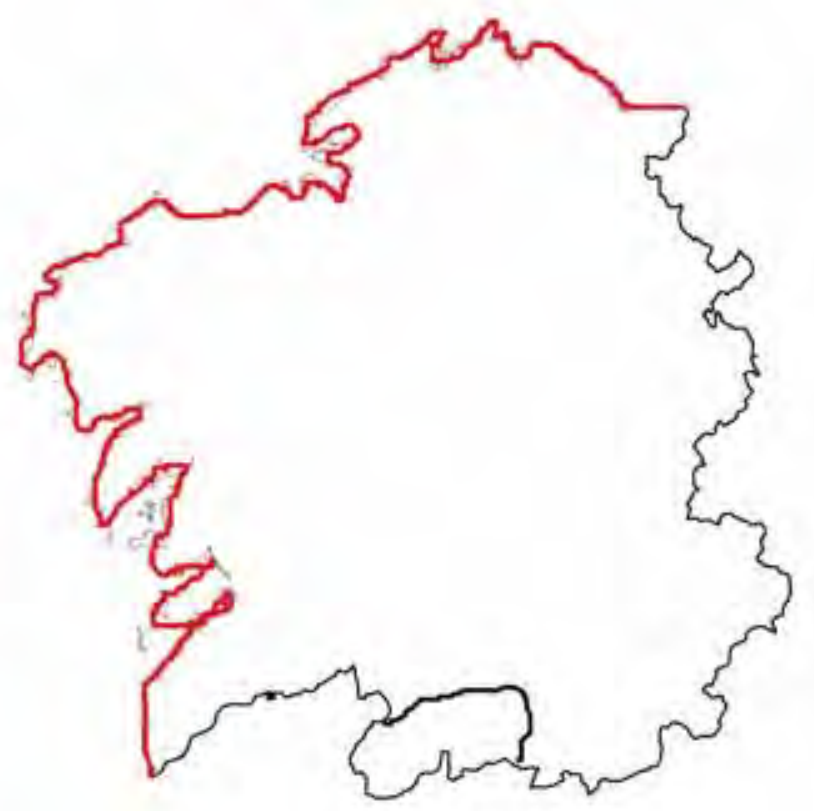

Mapa 3. Tipos de residencia matrimonial. En branco, mellora patrilineal e residencia patrilocal; en vermello, mellora matrilineal e residencia matrilocal; e, en negro, partillas igualitarias e residencia natolocal.

Coñezo casos, illados, en Castrofeito, que queda na zona de mellora masculina, nos que o matrimonio opta pola residencia natolocal. Nalgún caso porque os pais do vinculeiro non queren na casa a súa esposa; noutros, porque a esposa, a máis vella dunha familia sen irmáns varóns, decide quedar na casa paterna esperando recibir a mellora. Pero é unha solución que se enfronta á varios inconvenientes: a crítica dos veciños, que non a teñen como preferente; as notables distancias entre aldeas; e a prolongada espera, ata a morte dos pais, para iniciaren a convivencia. 


\section{A IDENTIDADE MÚLTIPLE}

$\mathrm{Na}$ cultura popular existen, pois, variantes locais nas que inflúe o medio xeográfico (tipo de pedra, clima, etc.) e a economía (nivel económico, tipo de traballo, etc.). Variantes que non son fixas, senón que cambian de acordo co momento histórico e o desenvolvemento técnico.

Poderiamos dicir que todas as parroquias, as 3.800, posúen trazos semellantes e trazos diferentes a calquera outra. Iso permite que unha parroquia se sinta, segundo lle conveña en cada momento, similar ou diferente ás demais.

En ningunha sociedade humana pertencen as persoas a un só grupo. A identidade sempre é múltiple, e máis múltiple canto máis complexa é a organización social. No caso galego a xente identifícase coa casa, a aldea, a parroquia e Galicia. Isto é posible porque calquera deses segmentos sociais posúe elementos peculiares e elementos comúns. Nunha aldea non hai dúas casas exactamente iguais, pero tampouco as hai que non compartan absolutamente nada; e o mesmo poderiamos dicir das aldeas dunha parroquia e das parroquias con respecto ao conxunto de Galicia. Son tantos os elementos culturais que compoñen unha cultura que non resulta difícil atopar, entre dous segmentos da estrutura social, algúns similares e outros diferentes. Estas semellanzas e diferenzas permiten que un segmento social, segundo lle conveña en cada momento, se sinta unido ou separado de calquera outro. Para sentirse unido, sempre contará con aspectos comúns; para separarse, nunca lle faltarán outros que os diferencian. Naturalmente, canto máis pequeno sexa o segmento social tomado en conta, maior será o número de elementos compartidos; e menor canto máis grande.

Se unha parroquia, por exemplo, non tivese ningún elemento diferente doutras parroquias carecería de personalidade propia; en cambio, se fose absolutamente distinta, en realidade non sería unha parroquia, sería outra sociedade e non formaría parte da cultura galega. 